\title{
Challenges on Technology Acquisition based on Absorptive Capacity of Composite Materials in Iran's Aviation Industry
}

\author{
Mohammad Hossein Sabour ${ }^{1 *}$, Mahdi Mohammadi ${ }^{2}$ and Erfan Khosravian ${ }^{1}$ \\ 'Department of Aerospace, Faculty of New Sciences and Technologies, University of Tehran, Tehran, \\ Iran; sabourmh@ut.ac.ir, E.Khosravian@ut.ac.ir \\ 2Faculty of Management, University of Tehran, Iran; memohammadi@ut.ac.ir
}

\begin{abstract}
Today, technology is presented for various reasons and is considered as a candidate for investment. Firms have to obtain technology for growth, competitiveness, product and service presentation, daily activities, meeting organizational damage, environmental, legal and governmental conditions, and many other reasons. One of the areas of science and technology that has a significant impact on improving living standards and serving the citizens is the airline industry which has an important role in improving the standard of living with the development in commercial and public sectors. One of the most important characteristics of this emerging industry is the multiplicity of application of new technologies, including composite structures technology. Entry of composite structures into the aerospace industry is for meeting its exceptional and unique needs, and it can be said that the perfect position and continuation of aerospace industry development depends on the progress of composites and the relevant techniques. One of the most significant parameters in the design of aircraft construction is the light weight along with good stability against the stresses and forces imposed which leads to reduced fuel consumption and increased payload, and specifies the position of these products in the aerospace industry. Absorptive capacity is defined as the ability to identify, acquire and apply knowledge in the environment, and technology acquisition is often referred to processes, strategies and using opportunities that provide the possibility of achieving desired goals in a short time. In this study, the most important issues and challenges on facing the composites industry are discussed in various domains including: Supply of raw materials, technology and production capacity, final market and product trade, business environment and political content of the industry. Finally, the impact of absorptive capacity on technology acquisition in the field of technology of composite structures is studied.
\end{abstract}

Keywords: Absorptive Capacity, Aviation Industry, Composite Materials, Technology Acquisition

\section{Introduction}

The plastics and resins and in more generally, fiber reinforced polymers are called composites. Composites known as fiberglass in the industry are an important class of engineering materials. These materials have good mechanical properties and good flexibility in their design and are easily built. Today, composites have such high performance that are used both in structural components and aircraft and spacecraft parts, from hot air balloons and drones aircrafts to passenger and combat aircrafts and space shuttles ${ }^{1}$. Sometimes, the whole plane is made of composites, sometimes only parts such as aircraft wings, helicopter propellers, airplane propeller, seats or interior decorators are produced using composites. Boeing has benefited largely from composite materials in designing and manufacturing wings and fuselage of the Boeing $787^{2}$.

In addition to $20-50 \%$ weight loss in above constructions, the use of composites in aviation vehicles has the following benefits. For example, using composite machining automatic methods, we can produce complex components seamlessly. It should be noted that for the

* Author for correspondence 
production of seamless hollow parts, in different shapes and sizes, the rotational molding technology is used. The seamlessly composite structures produced have high stability in addition to being light. On the other hand, composites have high thermal stability. Thus, by temperature changes, they do not experience so much expansion and contraction, so they are more resistant to cracks. Aircraft composite parts can tolerate high temperature changes for a few minutes at high altitude from ground level. Another feature of composites is the high stability against impact. For example, aramid fibers that are used in military aircrafts prevent significant damage to engine pylons when aircraft accidents occur. Using composites can also minimize the problems caused by fatigue and corrosion in aircraft structures (such as (racks) $)^{1-3}$.

Due to constant changes in the market such as changing customer preferences, reduced boundaries of industry, demographic changes, emerging competitions, new advances in technology, etc., countries and consequently the organizations in the context need quick and decisive respond and significant changes in business practices to avoid the risk of failure. This means that in today's world, access to raw materials, labor force, and proper capital in competition are not the only advantages, but technological capabilities and appropriate infrastructures upgrading these capabilities create the advantage $e^{4-8}$.

Therefore, the development of composite technology as an advance in the development of fuselage construction market has a special place and depends on the absorptive capacity of this field of technology in the aviation industry firms.

Absorptive capacity refers to the ability of knowledge discovery or internal new knowledge production ${ }^{9}$. It begins with understanding the specific opportunities ${ }^{10}$. A company or organization is a set of knowledge discovery processes. After creating new knowledge, companies have to integrate this new knowledge with their knowledge bases. The new knowledge is placed by linking to existing knowledge base ${ }^{11}$.

Some emphasize technological capability as a longterm source of competitive advantage and consider it as the driving force of innovation in firms, and say that it includes technological knowledge, trade secrets, and technological knowledge generated by the technological research and development and intellectual property such as patents12.

Some also have considered the issue of technological capability from the perspective of developing countries and suggested that in developing countries, due to lack of connection with users and advanced manufacturers, and remoteness of advanced sources in technological innovation, often innovation rarely occurs as a new meaning for the world ${ }^{13}$.

Instead, the process of technological change - as the acquisition and improvement of technological capability in these countries - is highly considered. This process involves learning to use and enhance the existing technologies in the industrial economies ${ }^{11-13}$.

Figure 1 shows the relationship between absorptive capacity and technological capability. In a broader view, technological capability is an inner adequacy that causes attraction, adjustment, reform and innovation of imported technologies which are involved in the process of technological change. In fact, technological capability is the ability to understand and improve the technology received. Some consider the technological capability as an inner ability in some specific organizational areas. Some of definitions look at this capability from the perspective of creating competitive advantages for firms.

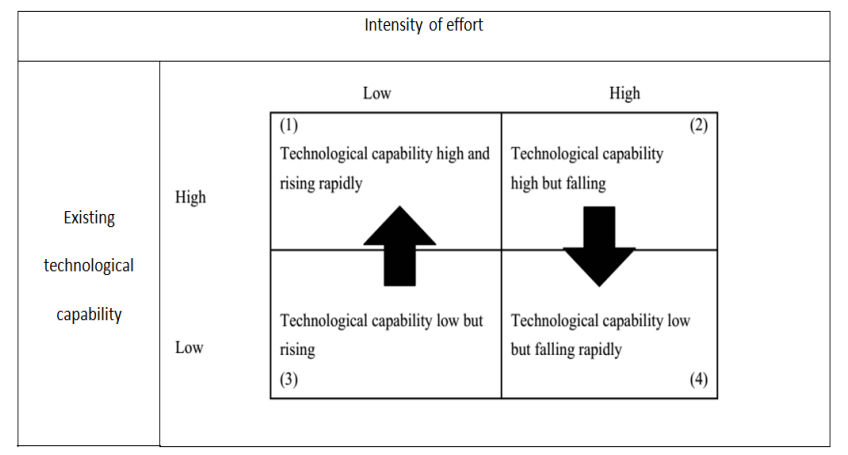

Figure 1. Relationship of absorptive capacity and technological capability.

While innovative capacity refers to the discovery of new internal knowledge, absorptive capacity explores the external knowledge. Accordingly, Cohen and Levinthal ${ }^{14}$ present their definition as the process of identifying, attracting and using foreign knowledge, and Zahra and George $^{15}$ explore the difference between potential of absorptive capacity and realization of absorptive capacity. Likewise, Lin et al focus on exploratory, disruptive and operator processes of learning ${ }^{16}$.

Following this reconceptualization, absorptive capacity focuses on knowledge acquisition in the framework of knowledge management capacity; for example, the absorptive capacity expressed by Zahra and George and exploratory learning raised by Lin et al. ${ }^{17}$. 
Since the focus on knowledge discovery processes does not guarantee successful knowledge commercialization as part of the knowledge operation processes, absorptive capacity is defined as the ability of a company to explore external knowledge ${ }^{18}$. Absorptive capacity in the framework of knowledge management capacity includes the process of accessing external knowledge and attraction of this knowledge using its combination with existing knowledge and technology $y^{18-22}$ and for absorptive capacity, we need relevant previous knowledge to understand the knowledge attracted.

\section{Research Strategy}

This study used a qualitative-quantitative combined approach. In this paper, the quantitative data collected are analyzed first. Then, using qualitative data, the subject will be analyzed more deeply.

In the quantitative part of the study, a survey was conducted among professionals of companies active in the composite industry and institutions responsible for development of the sector, and also analysis of documents was carried out and then the interview process was conducted. After the survey, subjects were selected for interviews. According to the passage of survey period, the possibility of providing deeper information to the interviewee was provided too. The advantage of this method is that at first, the survey does not allow researchers to have access to a broader set of participants, and interview process will ensure a deeper individual perspective ${ }^{23}$.

\section{Position of Composite Industry in the Passenger Aircraft Industry}

Because of high strength against high weight, composite structures are one of the propellants for the aerospace industry. We say that the perfect position and continuation of developing aviation industry depends on progress and techniques of composites. One of the most significant parameters in the design of aircraft construction is the light weight along with good stability against the stresses and forces imposed which leads to reduced fuel consumption and increased payload, and specifies the position of these products in the aerospace industry.

Since fuel prices are constantly increasing, commercial aircraft manufacturers have been required to enhance the effectiveness of their products and reduce fuel consumption and thus protect the environment. Reducing aircraft weight is a key factor which can help manufacturers in achieving both goals ${ }^{1-3}$. Figure 2 shows the effect of using composite materials in aircraft construction on its fuel consumption ${ }^{24}$. Using composites will cause avoiding the occurrence of corrosion in the aircrafts. Accordingly, the cost of repairs and daily maintenance of aircraft will be reduced dramatically. As a result, airlines that use every opportunity to lower their production costs can bring more products to market and outpace their competitors. This kind of competition can be also seen in military industry. In other words, aircraft and military missiles manufacturers must increase their load carrying capacity, diversity and product yield and provide security for occupants to remain competitive. Composites manufacturing technology is developing constantly and the emergence of advanced materials such as basalt fibers and carbon composite pipes that have high mechanical properties, has accelerated the use of composites in the aerospace industry. So we see that there are many applications for composites in the aerospace industry.

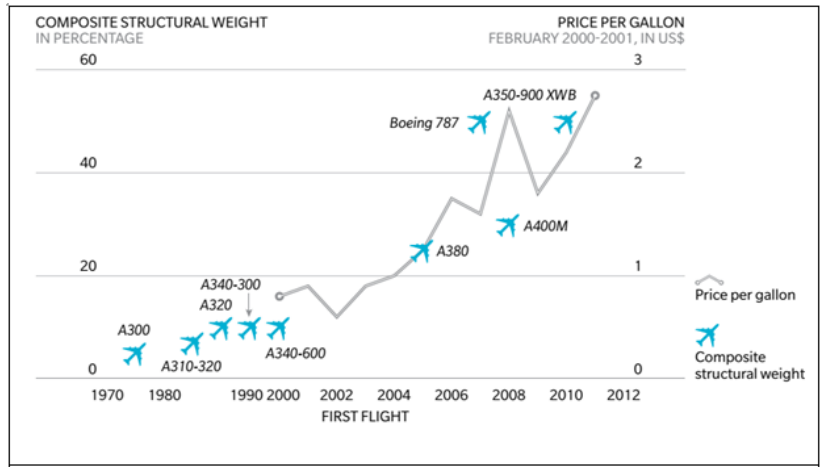

Figure 2. Effect of aircraft composite utilization on fuel price.

\section{Composite Industry in Iran}

Nominal production capacity generated by Iranian composite companies is $285 \mathrm{Ktons}$ per year. But, the actual production is not estimated at percentage. Distribution of composite use in various industries is different. Regarding to technology development, new consumption has created for variety of composite and the percentage of cases has changed. There are a lot of small company produced raw materials via manual method. Therefore, the accurate 
statistics about actual capacity of the producers of raw materials are not available. For example, according to data from the chamber of commerce, glass fibers imports were about 2.7 Ktons in 2012. Although nominal capacity of fiber companies was 29.8 Ktons inside just 4.5 Ktons were produced and 1.8 Ktons were not related to the composite industry ${ }^{25}$.

Although two or three decades ago, reinforced simple polymer composites with fiberglass entered the Iranian market, the composites industry in Iran is still on the way, and is facing problems that caused this useful engineering materials not to be considered much except in a few limited areas. Among the problems we can mention the supply of raw materials, lack of familiarity with the advantages of composite technology and lack of supportive legislation where the first issue is more prominent. The problem of securing polymers needed for composite industry is smaller than the problem of fiber preparation; because some of the country's demand is produced in domestic petrochemical industry, and there are no serious problems in the field of foreign purchases.

The composite industry supply chain structure in the aviation industry is shown in Figure 3. Key factors in each industry trend can significantly affect the success of the industry. As a result, it is necessary to identify these factors before industry analysis.

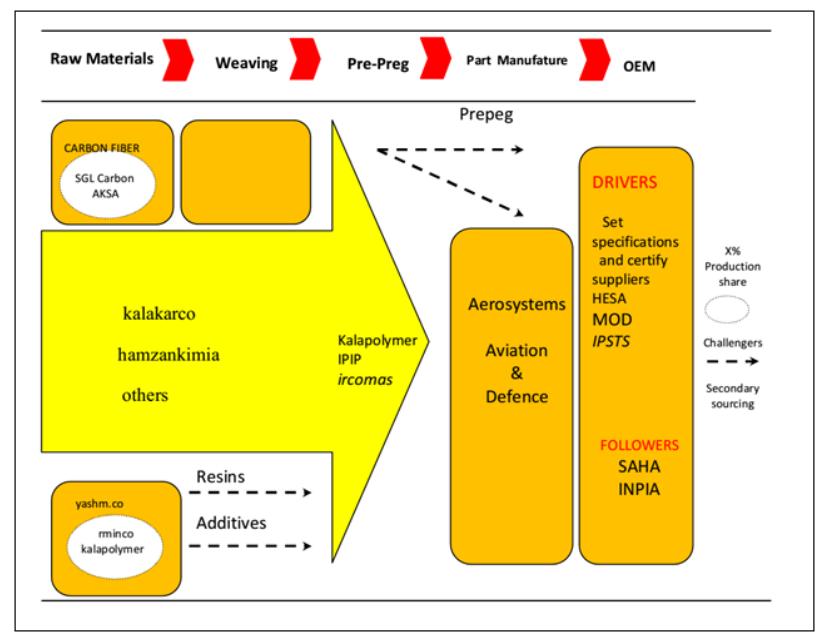

Figure 3. Composite industryvalue chain in aviatioan industries.

\subsection{Composite Industry, Per Capita Consumption in Domestic and International Markets}

Per capita consumption of composite materials in Iran is one-tenth of per capita consumption in developed countries. More than 6 million tons to the value of 145 billion dollars composite materials are used in various industries worldwide. Composite per capita consumption is $3 \mathrm{~kg}$ in developed countries while it is only $0.3 \mathrm{~kg}$ in our country. The proceeds from the sale of composite materials is 15 million dollars in return for $15 \mathrm{~K}$ tons and the average annual rate of $1 \%$ per year is projected ${ }^{26}$. In Figure 4, the use of composite materials in various industries is shown. Success in exporting unsaturated polyester resins to Europe by one of the Iranian resin manufacturing companies shows the high technical power and meeting international standards for such resin production in Iran.

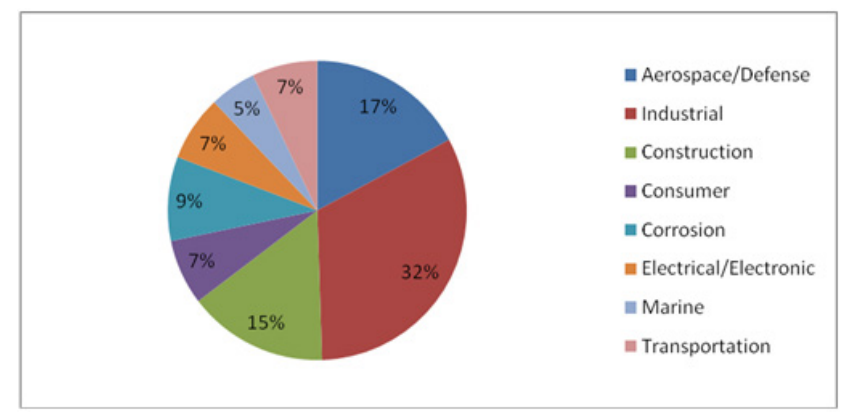

Figure 4. Use of composite materials in various industries.

Competing with global companies and manufacturers in the international arena is an area that our little experience indicates the need to pay more attention to the presence in the international arena through notification and participation in domestic and foreign fairs.

Iran's composites finished product is relatively at the same level as Asian countries (Figure 5). The reason for the low per capita consumption of composite materials in this continent is its breadth and also poor countries in the area. Meanwhile, Japan's composites finished product of 700 Ktons composites per year is as an example of an Asian developed country ${ }^{25-27}$.

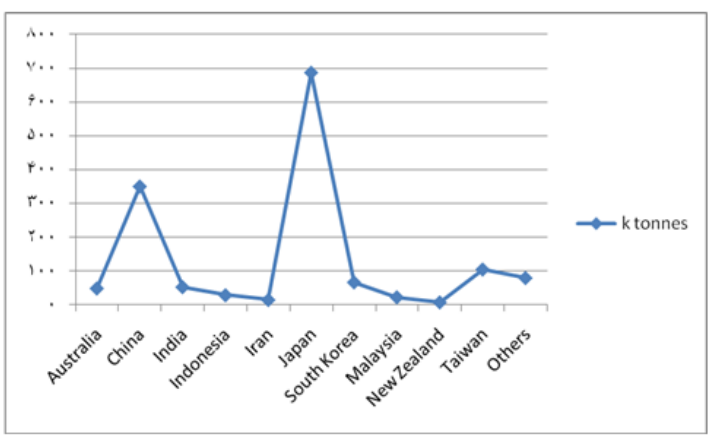

Figure 5. Asia-Pacific composites finished product tonnage by country. 


\subsection{Raw Material Producers}

The most important of raw materials are resins and reinforcements in Iran composite industries. There is no need to adjacent companies to raw materials site, however proximity to supplier of raw materials have an advantage, because the cost of transportation is saved. More than seventy percentage of cost of production is the cost of raw materials. Fiber glass production including vibration and damping characteristics of GFRP and BFRP technology process laminated composites ${ }^{28}$ faced with technological, financial and R\&D issues that should be supported by the government. Robust economy policy and shift to indigenous production can prevent from leaving the national capital. As well as transportation cost and tariffs that company should pay reduced. Figure 6 shows the various types of fiber companies. The companies with particular matrix materials ${ }^{25,26}$ are shown in Figure 7.

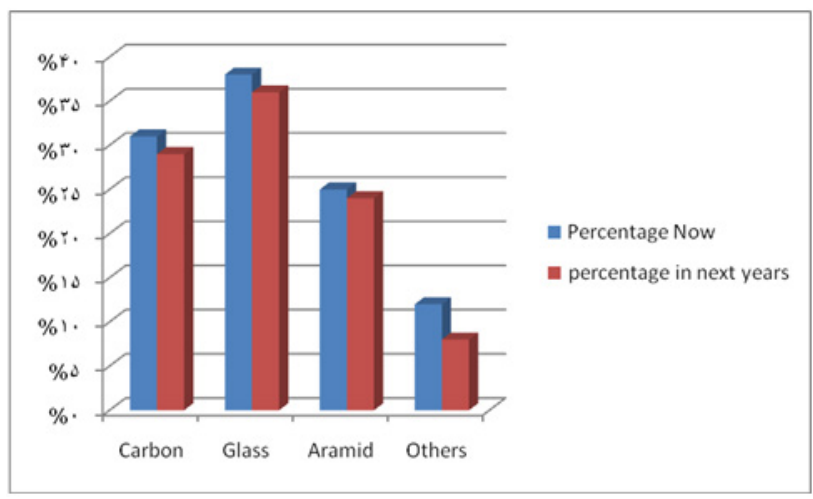

Figure 6. The fiber composite companies of Iran.

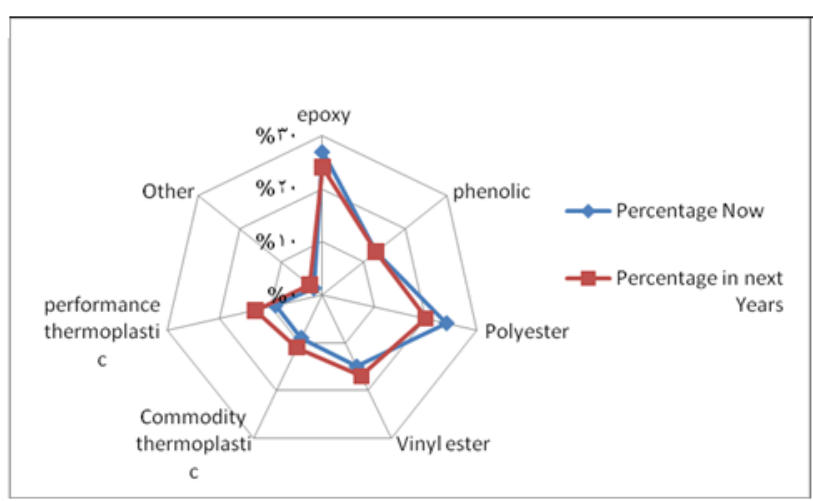

Figure 7. Matrix materials used by Iran composites companies.

Korea, China, Russia in Asia, and Germany, Turkey in Europe are main resin suppliers for Iran. Usually the quality and price of eastern and domestic raw materials are lower than western samples, and unfortunately, they have less stable properties. Of course, this is not a general rule and even for example, sometimes Russian Kevlar Fiber is much better than the American fiber.

Unfortunately, many aligned neighboring countries have surpassed Iran in the production of glass fiber. For example, the domestic need of Turkey which is one of the largest sources of glass fibers used in Iran is much less than the amount produced in the country. Turkey exports its surplus production to the market of countries such as Iran.

\subsection{Technological Trends and Technology Transfer Processes in the Composites Industry in Iran}

Some methods of producing composite parts include: Hand lay-up, spray-up, Sheet Molding Compounds (SMC) and Bulk Molding Compounds (BMC), GMT (Glass Mat Thermoplastic), Vacuum Bag Molding, Filament Winding, Pultrusion.

Most composite manufacturers in Iran produce their final products by hand lay-up and spray-up methods. This is due to the simplicity of these methods, need for limited basic equipment and the consumer market for final products. Vacuum Bag Molding process is of interest to producers due to the wide range of products. Pultrusion process requires a lot of equipment, but it is of interest in Iran due to the wide applications of manufactured products. BMC, SMC and GMT manufacturing processes are extensive used in Iran. It requires high technology, and some companies including NOURISTA Plastic are active in this field. Pultrusion technology which requires large amounts of glass fibers is created in the polymer research institute, and pultrusion machine is also built; pultrusion products are produced in pilot stage. If glass fiber is unavailable, this technology will be in serious trouble. Filament winding technology according to needs of mandrel to twist fibers is expensive process especially for production of large parts. Other technologies such as surface roughness for $\mathrm{Al} / \mathrm{SiC} / \mathrm{Gr}$ hybrid matrix drilling, compression molding and vacuum bags in compassion to filament winding are immature ${ }^{28-31}$. Figure 8 shows the compounds used by Iran composites Companies in now and future. 


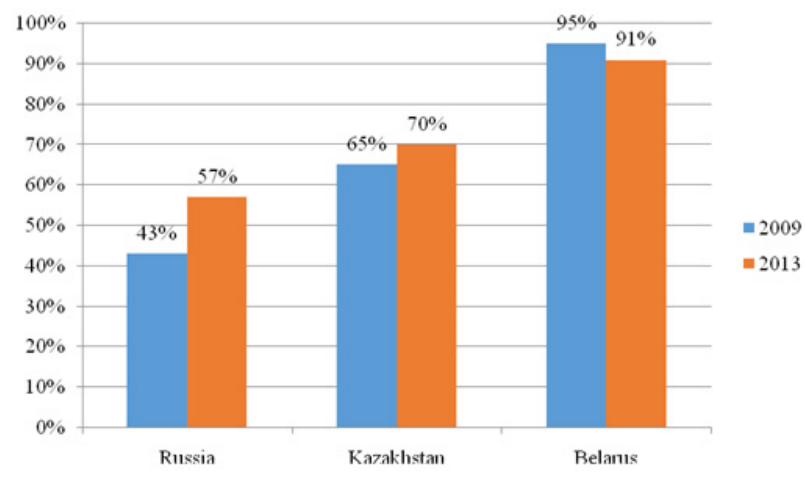

Figure 8. Compounds used by Iran composites companies.

Hand lay-up method needs the lowest financing and investment resources. After this procedure, spray-up process is in second place, because a machine is used spray resin rather than a hand. SMC and BMC manufacturing processes need a relatively high investment, because their manufacturing technology is usually non-native and technology transfer cost is considerable. Filament Winding process is capital-intensive due to the need for mandrel for winding fibers; the cost of the mandrel is expensive especially for large parts. Compression and vacuum bag molding processes are less expensive than Filament Winding. Pultrusion process requires substantial initial capital because it needs special equipment for traction.

Hand lay-up and spray-up methods need the lowest level of specialized training. However, due to the dependence of the final product quality on the skill of the operator, it is necessary for workers to undertake preliminary training and also have the sufficient experience and accuracy to produce high quality products. Pultrusion and filament winding processes require specialized training and presence of several technicians and engineers to manufacture flawless products seems necessary. In compression and vacuum molding techniques, skill comes first and it is better that the trained technicians monitor all stages of construction. In BMC and SMC manufacturing processes, due to the complexity of the procedure, it is necessary to give adequate professional trainings to operators to and the works be carried out under the supervision of engineers.

Resin Transfer Molding method is a commonly used method in the production of composite parts. However, the performance of parts produced with this method is low, and vacuum molding method and autoclave technique are used to improve the method and performance of parts. Using other manufacturing methods such as pultrusion and GFRP drilling ${ }^{31}$ is rising; injection molding and reinforce filament winding techniques also have higher levels of complexity. This method requires more investment, but will increase the accuracy and automation at the same time. High investment volume prevents many companies entering this field of complex technology.

\begin{tabular}{|c|c|c|}
\hline & \begin{tabular}{c|cc|c}
$\sim_{1}^{R \& D}$ & Rilot \\
\hdashline & & $\bigcirc$ & $\begin{array}{c}\text { Large-scale } \\
\text { stage }\end{array}$
\end{tabular} & $\begin{array}{r}\text { Fill-finish } \\
\text { process }\end{array}$ \\
\hline $\begin{array}{l}\text { 1. indigenous technology } \\
\text { transfer } \\
\text { (seed with know-how) }\end{array}$ & & \\
\hline $\begin{array}{l}\text { 2. preliminary design of } \\
\text { technology platform }\end{array}$ & & \\
\hline $\begin{array}{l}\text { 3. Pilot-stage } \\
\text { technolgical capability }\end{array}$ & & \\
\hline $\begin{array}{l}\text { 4. Large-scale production } \\
\text { or turn-key technology } \\
\text { transfer }\end{array}$ & & \\
\hline 5. Fill finish transfer & & \\
\hline 6. Stepwise transfer & & \\
\hline $\begin{array}{l}\text { 7. R\&D technical support } \\
\text { without mature concept }\end{array}$ & & \\
\hline $\begin{array}{c}\text { 8. Quality control/ quality } \\
\text { assurance technical } \\
\text { support } \\
\end{array}$ & & \\
\hline 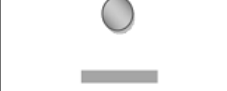 & $\begin{array}{l}\text { Transfer of composite specified technology } \\
\text { Self-development with support }\end{array}$ & \\
\hline ーーーー & Self-development & \\
\hline
\end{tabular}

Figure 9. Maturity of technology being transferred.

It should be noted that the formulation has a fundamental role in the production of composites. Especially in lay-up processes, according to resin curing at ambient temperature, formulation must be fully optimized to avoid premature resin curing during performance. This indicates the need for engineers to optimize the formulas. Selecting the appropriate style of technology development (including endogenous development, participatory development or product purchases) depends on the recipients and suppliers of technology development strategy, environmental factors such as international rules and regulations and government facilities. The cost of technology development, technology life cycle, competitive advantage, access time, importance of technology for supplier and receiver of the 
technology are of other factors that affect determining technology transfer mechanism. Higher technology receiver absorptive capacity leads to more successful transfer process. The schematic of maturity of transferred technology is shown in Figure 9.

In general, it can be said that not enough study has been done on ensuring proper technology, determining the type of technology and defining the desired level of main technology, identifying sub-technologies, determining the type of technology and defining the desired level of sub-technologies, and understanding the technology components. Iran's companies and sectors of technology supplier chain based on absorptive capacity are given in Table 1.

Table 1. SIran's companies and sectors of technology supplier chain based on absorptive capacity

\begin{tabular}{|c|c|}
\hline $\begin{array}{l}\text { Technological } \\
\text { absorptive capacity }\end{array}$ & Example \\
\hline $\begin{array}{l}\text { Upstream transfer (seed } \\
\text { with know-how) }\end{array}$ & $\begin{array}{l}\text { Nemagostarealborzm Co, Man- } \\
\text { ufacturer of composite parts } \\
\text { with High-technology composite } \\
\text { process }\end{array}$ \\
\hline technology platform & $\begin{array}{l}\text { Hb composites Co, production of } \\
\text { types of composite aviation part } \\
\text { and tubes }\end{array}$ \\
\hline Pilot-stage transfer & $\begin{array}{l}\text { IPPI, Production of thermoplastic } \\
\text { honeycomb sandwich panels in } \\
\text { semi-industrial scale }\end{array}$ \\
\hline $\begin{array}{l}\text { Large-scale production } \\
\text { or turnkey transfer }\end{array}$ & $\begin{array}{c}\text { Rminco, Construction of industrial } \\
\text { parts by autoclave process }\end{array}$ \\
\hline $\begin{array}{l}\text { Single recipient joint } \\
\text { development with ac- } \\
\text { tive input by facilitation } \\
\text { entity }\end{array}$ & $\begin{array}{l}\text { Aryamin Co, polyester \& vinyl } \\
\text { ester process techonolgy }\end{array}$ \\
\hline Stepwise transfer & $\begin{array}{c}\text { Sazehmorakab Co, aero structures, } \\
\text { aviation parts }\end{array}$ \\
\hline $\begin{array}{l}\text { technical support or } \\
\text { joint R\&D development }\end{array}$ & $\begin{array}{l}\text { Iran composite institute, Thermo- } \\
\text { plastic composite, natural fibers }\end{array}$ \\
\hline $\begin{array}{l}\text { Quality control/quality } \\
\text { assurance technical } \\
\text { support }\end{array}$ & $\begin{array}{c}\text { Santam Co, machine \& equipment } \\
\text { for quality control }\end{array}$ \\
\hline
\end{tabular}

The gap between available composites industry technology in Iran and the developed countries is low. Despite sanctions, access to new technologies is possible except in certain cases. And if economic stability, belief in the rule of law and the development of industry and support for industry in the country increase and manufacturers feel low risk for investment, obtaining this technology is not very difficult and certainly, industry will be able to solve all the problems. Getting new technologies is not as difficult as the adoption and achieving industrialization seem. Productivity level of technologies used in the Iranian composite industry, according to the type of products and the state of technology in the world, is potentially very high and only faces difficulties in the field of complex technologies. But the lack of necessary support for the industry and absence of efficient management to balance supply and demand in the industry, have caused manufacturers to fear from lack of demand despite high-tech machines. This has led to a very high level of potential productivity and low de facto level.

\section{Determining the Challenges and Strategies Affecting the Development of Composite Firms' Absorptive Capacity}

This section outlines some of the factors affecting the composite firms' absorptive capacity obtained from interviews and surveys. These factors can be divided into two general categories:

1. Internal factors including the size and structure of the organization, strategies, existing knowledge bases and organizational understanding.

2. External factors including the external environment where the knowledge must be acquired from, the position of the firm in the scientific network and the role of individuals, universities and the Institutes of Research and policy-making and government supports.

\subsection{Monitoring the Environment for New Technologies}

Environmental monitoring can be one of the main activities and processes in recognition strengthening. Monitoring the environment to determine the flows in the environment can make aware of the available technologies and also new ones. One of the problems that composite firms in Iran are facing is the lack of information and transparency of information. For example, due to lack of information on current conditions and trends, technologies may enter that are not in good condition in terms of life cycle and are considered as 
outdated technologies in the international environment, and this technology may enter the country in one of the areas (with any condition) and the same technology may reenter the country with the same conditions due to lack of information or lack of information integration. This can waste resources and time and involve many facilities.

Therefore, monitoring the environment to better understand the technologies and assess the needs and adapt the needs with technology can be preventive measures for many of the problems which likely will happen in the future. Environmental monitoring is one of the main activities done in many leading countries in technology, because with information about the current and future trends, we can direct the ongoing programs or strategic plans for the future and put resources in the right direction.

\subsection{Full and Explicit Compliance with Technological Trends}

Another interesting pattern and process can be full and explicit compliance with technological trends. This means that in the ideology, technology, investment, etc. and generally all activities that will lead to presentation of a new technology, there will be a series of processes and procedures, and full and proper compliance with the procedures and principles can fill many behavioral gaps in the area technology and speed up the process. For example, it can be said that in many developed countries leading in technology, technology policy-making and creating process infrastructure are known as the first step; and determining all the conditions and analytical studies, needed background is provided for beginning of each activity. At each step, alternatives needed for decision-making and decision-making bodies, policymaking and investment are clear, and everywhere on the way, all inputs and output can be monitored and investigated. Unfortunately, due to lack of appropriate technology infrastructure in Iran, where the most banal and crucial one is the national innovation system, passing the right direction and foundations of decision-making, investment and policy-making have been always debated in Iran, and can vary according to conditions. Presence of these conditions can lead to confusion and waste time and resources. The recommendation that can be presented in this area is: Creating a process and united center for decision-making, policy-making, investment in the field of composite technologies on all elements and activities related to the composites industry, and technological and innovative activities and monitoring all centers, incubators, technology parks, etc.

\subsection{Observing Details of New Technologies in External and Internal Resources}

Overviewing many of the components of new technologies, especially in the field of composite technology, we can see that many new technologies have been achieved from combining to changing the arrangement of elements and components of previous technologies. As it was mentioned in the variety of innovations, delivering something that did not exist before is not necessarily called invention. Reconceptualization of the previous content may lead to a new creation. Therefore, observing the details of the new presented technologies can provide a window of opportunity if it is done timely. One of the things that need to be considered is independence of the path and having flexibility. In this case, using the opportunities, it can be hoped that in addition to increasing the speed, we can use the advantages of initial login.

One of the main problems of composites industry in Iran is the lack of timely attention to the current changes and trends in the international level. It seems that everybody acknowledges the wrong path of the industry in Iran, but nothing is done to correct it. And the only cure at any time when the gap with the leading countries is getting broader is to import the new technologies. It seems that in this period, the falsity of this type of decision is no secret. It is true that the solutions to deal with this problem seems easy but requires a change in thinking and infrastructures. One of the things with existing infrastructure in the country (due to a strong academic body and research centers in the country) is investment in the country's research sector. Of course, this presupposes that research must be done on selective and investigated routes and technologies. For this, a process must be created that permanently monitors the ongoing technology trends and events in the leading countries, and always considers a type of need assessment and fault finding. Although, certain domestic and political trends should not be ineffective in the diagnosis and understanding of local conditions, many decisions must be measured within the framework of the political situation of Iran. Perhaps many methods are totally useless, destructive, or vice versa considering the overall limitations and interests of the country. 


\subsection{Collecting Detailed Information on Industry}

As stated in the monitoring of the environment, one of the main problems suffered in Iran is the lack of transparency and access to information. For example, many problems in the petrochemical sector faced in previous years, where various petrochemical industries got the same licenses and paid exorbitant costs in this area, and there were no center to monitor these cases, in order to activate $R \& D$ centers for other centers for development and localization of the technology, when a license is gotten by a center.

Many examples of this kind can be seen in the composite industry, and many technology companies that are active in composite technology, import technologies that are imported by similar companies for many times. More importantly, all these companies are under the supervision and support of upstream organizations and composite technology headquarters. This problem can be solved by coordination between departments.

\subsection{Management Orientation towards Learning}

Learning as an integral part of the technology components has been one of the missing rings of composite industry in Iran. In our country, composite technology hardware has been more focused and learning and skills have been neglected. If the contribution of this essential element in the country's composites industry be focused in the downstream levels that can be organizations and companies active in the composites industry's technologies, we can see positive results because the Iranian academic body in the composite sector is strong enough, but the relationship between the body and the executive science and technology is very poor. Perhaps the reference to the role of government to create the conditions and changes in education in the country can be expressed by many experts, but if we create tendency to learning in the micro-levels and management of organizations and companies, it seems that there can be significant changes in the composites industry technologies in the short term.

\subsection{Research and Development Cooperation and Cooperation Projects with Companies and Research Institutions}

One of the frequent methods and practices in the last few years in the leading companies in composite technology which are even each other's main competitors is building cooperation and joint research and development. Examples of this cooperation can be found at the national level. In addition to appearance discussion, joint cooperation can affect many upstream and downstream areas and provide opportunities for cooperation in many other fields and create cautions regarding the behavior for the other side. Because of some benefits, the other side may not attempt to perform non-constructive behavior. The recommendation for organizations and companies linked to the composite technology in Iran is to make short- and long-term partnerships with composite technologyleaders in the world. In addition to the technology overflow that occurs during the period of cooperation, this will transfer behavioral style and technological culture to the country. Another important issue can be the rapid information about the currents trends and up-to-date technologies in the world. In addition to the direct impact on composite technology, research and development cooperation can affect the entire industry, and increase the speed and reduce the gap of technology in a shorter time. Another notable point at the national level is the creation of research and development cooperation that makes the behavioral requirements with regard to relations with Iran for other countries, and due to certain circumstances of Iran, this point can be considered as a way to reduce the destructive behavior of the developed countries. But it is also important to note that throughout the process, there should not be fully relied on and trust the other side without consideration. We should always behave in a way that if the relation is cut at any time, the possible loss of benefits and losses may occur at the least level.

\subsection{Increasing the Knowledge of Competition}

Maximum use of opportunities ahead of the competition has been always the factor that has made the position. Deluding the way of competitors' business practices at the international level can do a lot of damage in terms of loss of capital facilities and also time. Using international experience and leading expertise can help spending facilities, capital and time in the right direction and increase speed and reduce the gap with the leaders. We can use the experiences of the first entries, and knowing the advantages and disadvantages of the traveled route, 
we can maximize the advantages and prevent the occurrence of disadvantages. The experiences also stated that one of the strategies of successful companies is the permanent monitoring of processes. They investigate and review along with the leaders and allow them to enter. And immediately, in a short time, understanding the conditions and environmental responds, in addition to the corrective measures, they boost the investment points and decide to enter with better conditions.

\subsection{Technological Absorptive Capacity}

Having the capacity to receive is a prerequisite for any planning and policy-making, because without having substrates and capacities required, there will be no initial requirement for planning. Building capacity is like the interlinked rings of a chain that will include several cases, and by making all these centers and infrastructure together, it can be said that capacity required exists. These capacities will be offered in three parts. The first part consists of skilled manpower that requires a strong academic departments and also scientific and applied centers. In this sense it can be said that academic sector has a strong base in Iran, but there are communicational and structural problems, and it is the lack of matrix and structural relation for operating the sciences. The second part is the required skills that need strategic and institutional partnerships that help researchers gaining experiences. These structures include academic research centers, incubators, technology and science parks, research and development institutions in the public and private levels, etc. Some actions have been taken in terms of these centers in our country, but these centers must be closely associated to use each other's output; but, unfortunately, each of these categories has been working independently for themselves due to poor internal management and the absence of a national program and a developed structure. Unfortunately, a path and methods of trial and error are repeated many times and time and resources are wasted to the maximum extent possible. The third part is the hardware requirements, and again it can be said that the only way to obtain this sector in our country is to import, and finally, all programs are summed to get the license. Therefore, it is proposed to use consultants to solve this issue; this consultation can be done at the international level, but in general level, it can be concluded that previous methods might have a minimum efficiency in current conditions.

\subsubsection{Openness to the Environment}

In many international studies, openness has been introduced as one of the main ways to explore the environment. It is stated that the relationship with the environment can be one of the main ways to discover ongoing trends. It is worth noting that one of the pillars of open innovation is openness to the environment. The recommendation raised in this study is based on existing organizational structures and composite technology companies in Iran, and creating units for relations outside the organization internally and externally, which can also provide initial conditions for joint cooperation.

\subsubsection{Periodic Meetings with the Industry and Information Exchange}

One of the main problems of composites industry in Iran is the lack of information on industry conditions and the current situation, as well as lack of knowledge and familiarity of Iranian craftsmen with new and updated technologies and the benefits generated and advantages of new and updated technologies. According to the existing structure in Iran, periodic industry meetings and ideas exchange, the recommendation raised can help in the understanding of the parties of the conditions and provide a platform to allow the science and technology into the industry.

\subsubsection{Shaping the Approach of Human Resources for Regular Interactions to Gain Technology Knowledge (Intersecting Relations to Exchange Knowledge, Make Ideas and Solve the Problem)}

One of the solutions proposed in this study is the human force interactions and internal structure. This argument can be derived from management approaches. It seems that communication problem in Iranian organizations and in this case, in the composites industry is the complexity of technology, and the need for a different structure in human force relations. Creating intersecting and informal relationships is necessary to create innovative and ideamaker environments.

\subsubsection{Correct Transfer of Technology in Response to Technology Acquisition Opportunities}

Another solution proposed is using the advantage of the 
opportunities occurred is consistent with local needs. In this case, the correct and timely transfer of up-to-date technology can activate more research and development centers to expand and develop new transferred technologies. It can also be of great importance in dominating the new technologies.

\subsubsection{Creating Knowledge Absorptive Capacity and Organizational Self-Awareness in Human Resources}

Paying particular attention to human resources is one of the main outputs and results. Human resource is known as a key element in the technology and without strong and skilled human resources and qualified specialists, even with strong hardware and up-to-date knowledge, we cannot dominate technologies. In fact, in many cases, strong human resources have been the source of great developments in technology with the least facilities. In Iran, due to special circumstances and political sanctions by many countries, paying attention to human resources can partially cover many other elements. We should try to equip human resources with self-awareness to understand the technology and also create ideas and make innovation as a kind of organizational culture among people. In this case we can ensure that ongoing processes will go ahead with maximum efficiency in organizations and companies. Focus on human resources in organizations and companies associated with composite technology in Iran can be formed in different ways; of course, each of these solutions is not only accountable and needs these processes to be considered together in parallel. One of the solutions suggested is using academic centers' output and experts trained in these centers. In this way, expert forces can be entered into the system, and another approach is to provide sciences and training needs for other forces by holding constructive training courses. The manpower who has a kind of self-awareness can be one of the main assets of all companies. This manpower always considers a kind of commitment to innovation in his own behavior and will increase the rate of progression in organization.

\subsection{Stability of Governmental Decisions in the Field of Composite Industry}

According to many experts and connoisseurs of composite industry, impulsive and impractical decisions at the state level, lead to a lot of problems in the industry level. For example, some cases are mentioned in this section:

Importing goods: In some cases, authorities determine the tariff rate regardless of the commodity usage. In the meantime, the same product may be used as raw material for other products in the industry, and the increase in tariff rate increases the cost and rate of supply of the product. In order to support the industry and if the imported good has the same domestic production, the tariffs on imports are raised. But whether the quality and quantity of locally produced goods could meet market demand is ignored. Reasonable balance in this field will be very effective.

Revenging perspective of tax laws: Orientation of tax laws has provided the possibility of abuse for a group, so, with the knowledge about this matter, tax laws have become revenging. Progressive taxation with the ratio of turnover growth, and considering it as tax for next year have led some manufacturers not to declare all transactions to reduce taxes. There are no tax incentives for producers having growing activity and employment. As a result, tax return of manufacturers is done with discretions.

The absence of reasonable rules on customs: This has led customs officials to deal with importers with discretions, while the customs officials are merely law enforcement officers and should not enforce them with their own inference and idea. That's why clearance is done easily in some customs and hardly in some others. This can lead to administrative corruption.

\subsection{Failure to Allocate the Promised Subsidies to Industries}

Lack of financial commitment of public or governmentrelated employers or apparently private: These employers obtain all kinds of commitment and guarantee from the manufacturer or supplier for delivering the ordered goods, and in case of delay in delivery, penalties are deducted. But they have no commitment to pay contract funds and even have violations for months or years which leads to manufacturer's loss. Termination and suspension, a contract with instant decisions, lack of attention to losses incurred to the manufacturer as a result of this decision, s-sided contracts to the detriment of producers, lack of timely payment of contract funds after the implementation of the obligations of contractors and manufacturers are evident in this area.

Incorrect modeling from foreign countries in 
development: It should be noted that in the planning, the economic situation of the domestic producer is evaluated on the basis of economic situation in the country, and decisions are made. Domestic producers are currently faced with many risks and need support (sanctions on one side and the situation of internal rules on the other hand). Therefore, comparison with foreign producers or compliance of laws with international laws regardless of domestic economic conditions is not professional.

In general, it should be noted that the government's role in sustainability must become a supporter and facilitator, and its ownership and control role must be lowered. This is consistent with the spirit of the Constitution of the Islamic Republic of Iran and the strategic policies on one hand, and global trends governing the interaction between government and industry, on the other hand.

Foreign Knowledge Management: Foreign knowledge as well as international investigation processes should be monitored carefully. There is no certain database for composites industry in our country to collect all the information in the field of composite technology and to be used by all companies and organizations and volunteers for entering the arena. The existing sources are heavily suffering from lack of resources and outputs are available to certain people. One of the recommendations of this study is to create a consulting database for all organizations and companies operating in the field of composite materials technology and all those who are interested in the industry.

Ability to rapidly analyze and interpret the changes and demands in the market: Ability to meet the needs of the market can be very important for the composites industry in Iran. First, there's a very large market in Iran; second, Iran is geographically located in an area with potential markets and few competitors. Responding to market needs, in addition to expanding business could provide grounds for active participation. The economically stronger organizations and companies can allow spending more costs for research and accepting higher risks for early entering. Composite organizations and related companies are recommended to pay more attention to market movements and needs according to its capabilities. In this case, by providing services, appropriate responses can be received from the market.

\section{Conclusion}

Technology acquisition with absorptive capacity approach is a diverse collection of abilities that companies need to acquire, assimilate, use, adapt, change and develop technologies, and is due to activities that can be performed repeatedly. Absorptive capacity is established as an organizational capability by the processes or organizational routines. In fact, capabilities are representatives of routines' packages and organizational solutions. Generally, when the unique assets of a company are integrated among individuals and groups, they launch distinctive activities to be run, and then a capability or competence is formed. These activities include routines and organizational processes.

These dimensions are affected by the type of technology, market and environmental conditions. In other words, continuous creating, promoting and reconfiguring of technological absorptive capacity as an important capability task in the organization require something more than the usual technical, engineering and research capabilities which are emerged in complex organizational processes and approaches prevailing in each firm.

The need to understand the requirement for change as one of the key factors of absorptive capacity of composite materials companies technology as a hi-tech sector is among other results of this research. Basically, the companies active in the field of composite materials require continuous rebuilding of their technology capabilities due to the specific structure of technologies in this area and its changing environment. Therefore, acceptance of change as something fixed in this category practically changed the behavior of the firms and leads them to accept the terms governing the transition environments instead of stable environments, and the most important achievement is the organization movement to creation of a kind of dynamism in its own processes, which allows it to mobilize resources within a short period to take advantage of environmental transient opportunities in variable space.

Composite materials companies in Iran require some form of business and technology intelligence to improve their technological capability in order to well understand the environment and its developments. A very important point that is reflected in the current research and especially qualitative samples is the dependence of such intelligence on the time and the path passed by the company. In general, where any company can go depends on its current situation the paths ahead. This concept is difficult to explain and it is one of the main limitations of economic and management theories. Previous investments in 
processes and organizational routines form the future behavior of the organization. This is because learning is an internal affair which roots in the previous activities and the process of testing, feedback and evaluation. Thus, organization's intelligence is something that must be learned in different parts of the organization and it should be considered in each company, and it cannot be divided into specific sub-dimensions.

Due to the highly variable environment, composite structures companies must have agility and the ability to exploit transient environmental opportunities, but companies' resources are limited on the other hand. Therefore, this limitation requires companies to have the ability to be separated from their existing technologies in order to enter new areas of technology, so, they must have a technology roadmap that will respond to the future needs and will identify the entry and exit points. The organization should also be dynamic and accept changes and take steps faster than others, so it needs a motivation-based leadership. Therefore, taking into account the technology acquisition patterns with absorptive capacity approach, policy makers in this field can set the indicators of companies' entry into the industry's supply chain. Modification of presentation of facilities to the knowledge-based companies related to composite materials in order to enhance the companies' technological capabilities is of other recommendations of this research. Undoubtedly, the provision of physical facilities alone is not sufficient to improve the companies' technological capabilities, because this type of aid relies largely on increased resources, which is the last ring in the competitive advantage chain in firms, and so it is not dynamic and continuous. Presentation of facilities associated with the promotion of companies' dynamic capability is of the most important facilities whose samples exist in developing countries. For example, creating smart systems in the country's airline can a part of the facilities provided to these companies, which are mostly small and medium. By this highly advanced business and technological smart system, these companies are aware of the latest developments in the market and technology with a very low cost. Also, providing management training and establishing management consultancy companies in the field of composite technology can be very useful and productive.

In this regard, the role of innovation clusters and aviation technology parks in the field of composite materials is very important. In general, international certification and approvals for production and assembly of components in the passenger sector is of great importance. Receiving international approvals needs two sectors of routines and processes confirmed and then testing. The routines and processes sectors can be obtained by the establishment of international standards systems in various fields, but one of the main challenges is testing with international reputation. For these kinds of tests, highly advanced and expensive infrastructures and laboratories are needed. Having clusters or aviation technology parks with the support of public and private sectors which could provide the necessary infrastructures for these stages based on a clear roadmap is of the most important needs of the industry to develop technology capabilities.

\section{References}

1. Hull D, Clyne TW. An introduction to composite material. Cambridge University Press; 1996.

2. Walz, Martha. "The Dream of Composites". RD mag. Nov 20, 2006.

3. Smallman RE, Bishop RJ. Modern physical metallurgy and materials engineering. Butterworth-Heinemann: USA; 1999.

4. Caloghirou Y, Kastelli I, Tsakanikas A. Internal capabilities and external knowledge sources: Complements or substitutes for innovative performance?, Technovation. 2004; 24(1):29-39.

5. Smith A. The wealth of nations. Modern Library: New York; 1776.

6. Karl M. Capital, Modern Library: New York, 1867.

7. Schumpeter JA. The theory of economic development: An inquiry into profits, capital, credit, interest, and the business cycle. Transaction publishers: London, UK; 1934.

8. Nelson RR. Understanding technical change as an evolutionary process. North-Holland: Amsterdam; 1987.

9. Lane PJ, Koka BR, Pathak S. The reification of absorptive capacity: a critical review and rejuvenation of the construct. Academy of management review. 2006; 31(4):833-63.

10. Lichtenthaler U, Lichtenthaler E. A capability-based framework for open innovation: Complementing absorptive capacity. Journal of Management Studies. 2009; 46(8):131538.

11. Kim L. Imitation to Innovation: The dynamics of Korea's technological learning, Harvard Business School Press: Boston, Mass; 1997.

12. Mistree F, Smith WF, Bras BA, Allen JK, Muster D. Decision-based design: A contemporary paradigm for ship design. Transactions, the $98^{\text {th }}$ Annual Meeting of Sname, San Francisco; 1990. 
13. Lall S. Building industrial competitiveness in emerging countries, OECD: Paris; 1990.

14. Cohen WM, Levinthal DA. Absorptive capacity: a new perspective learning and innovation, Administrative Science Quarterly. 1990; 35(1):128-52.

15. Zahra SA, George G. Absorptive capacity: A review, reconceptualization, and extension, Academy of Management Review. 2002; 27(2):185-203.

16. Lin C, Tan B, Chang S. The critical factors for technology absorptive capacity. Industrial Management and Data Systems. 2002; 102(6):300-8.

17. Lin C., et al. The alliance innovation performance of $R \& D$ alliances. The absorptive capacity perspective. Technovation. 2012; 32(5):282-92.

18. Mohamadi M. Maturity model for assessing the technological and innovative capabilities of the firm. International conference on engineering, technology and innovation-IEEE TMC Europe Conference, Bergamo; 2014.

19. Lenox M, King A. Prospects for developing absorptive capacity through internal information provision. Strategic Management Journal. 2004; 25(4):331-45.

20. Burgelman RA, Maidique MA, Wheelwright SC. Strategic management of technology and innovation. (2nd Ed.), IRWIN: Chicago; 1996.

21. Nalura R. Globalization and Technology: Interdependence, Innovation Systems Industrial Policy, Polity Press: Cambridge, UK; 2003.

22. Lall S. Promoting technology development: The role of technology transfer and indigenous effort, Third World Quarterly. 1993; 14(1):95-108.
23. Zikmund, William G. Business research methods. Fort Worth: Dryden Press; 2000.

24. Aerospace Global Report 2014 IMAP; Usine Nouvelle; Oliver Wyman analysis.

25. Iran composite industry analysis. 2015 Jun 12. Available from: www.nipc.ir/uploads/kholase_compozit=2.pdf

26. Analysis of the position of Iran in global exports of high technology goods by commodity groups. Islamic Republic of Iran, Ministry of Industry, Mine and Trade. Available from: http://www.mimt.gov.ir/

27. Global unsaturated polyester resin market 2015-2020: Trends, forecast, and opportunity analysis. Lucintel. 2015. p.71-85.

28. Alexander J, Augustine BS.M. Free vibration and damping characteristics of GFRP and BFRP Laminated Composites at Various Boundary Conditions. Indian Journal of Science and Technology. June 2015; 8(12).

29. Munia Raj A. Experimental investigation and analysis of torque in drilling $\mathrm{Al}-15 \% \mathrm{SiC}-4 \%$ graphite metal matrix composites using response surface methodology. Indian Journal of Science and Technology. Oct 2014; 7(S6):87-94.

30. Rajamurugan TV, Shanmugam K, Palanikumar K. Mathematical model for predicting thrust force in drilling of GFRP composites by multifaceted drill. Indian Journal of Science and Technology. Oct 2013; 6(10):5316-24.

31. Munia RA, Das SL, Palanikumarr K. Influence of drill geometry on surface roughness in drilling of $\mathrm{Al} / \mathrm{SiC} / \mathrm{Gr}$ hybrid metal matrix composite. Indian Journal of Science and Technology. July 2013; 6(7):5002-7. 